\title{
A Pesquisa com Seres Humanos e os Mecanismos de Controle Social *
}

\author{
Anderson de Fraga Pereira** \\ Selma Rodrigues Petterle***
}

\begin{abstract}
1 Breves notas introdutórias. 2 Controle social na saúde: o papel das conferências e dos conselhos de saúde. 3 A discussão do tema no Município de Canoas/RS (Conselho Municipal de Saúde e Conferências municipais de saúde) e Conferências Nacionais de Saúde. 4 Considerações finais. Referências. Apêndice. Anexo.
\end{abstract}

\section{RESUMO}

A Constituição brasileira de 1988 protegeu um conjunto de direitos sociais, dentre eles, o direito à saúde, sendo que o sistema de saúde no Brasil é organizado por meio de um sistema único que, dentre outras características, deve ter a participação da comunidade. Essa participação ocorre fundamentalmente por meio dos conselhos e conferências de saúde. Em âmbito nacional, o Conselho Nacional de Saúde tem sido o órgão normatizador das diretrizes que orientam as pesquisas envolvendo seres humanos, mais recentemente a Resolução 466/2012. Considerando essas premissas, o presente artigo objetiva verificar em que medida se deu a discussão, junto ao Município de Canoas/RS, a respeito do conteúdo da referida resolução, com a pesquisa documental nas atas de reuniões e assembléias.

Palavras-chave: Saúde. Controle social. Pesquisa. Seres humanos.

\section{BREVES NOTAS INTRODUTÓRIAS}

A problemática da pesquisa com seres humanos é recorrente e está permanentemente incluída na pauta das discussões. Em termos históricos, há que destacar dois instrumentos no âmbito do direito internacional, dentre outros, ${ }^{1}$ no que diz respeito à pesquisa com seres humanos: o Código de Nuremberg e, posteriormente, a celebração do Pacto de Direitos Civis e Políticos (1966).

* Artigo decorrente de projeto de pesquisa com fomento externo, Edital Universal CNPq, no $13 / 2014$.

** Bacharel em Direito pelo Centro Universitário La Salle, UNILASALLE. E-mail: anderson. infoservice@gmail.com.

*** Docente permanente do Curso de Mestrado em Direito do Centro Universitário La Salle, UNILASALLE, Canoas-RS. E-mail: selmapetterle@gmail.com. 
O primeiro consubstancia o julgamento de Nuremberg, em 1947, após o término da Segunda Guerra Mundial, dos crimes cometidos pelos médicos nazistas nos campos de concentração, que foi um ponto de partida para elaborações posteriores. Eis alguns ilustrativos exemplos desses experimentos: ingestão de água do mar, para verificar quanto tempo uma pessoa conseguiria ficar sem beber água fresca; submersão de prisioneiros em água gelada, para calcular o tempo de sobrevivência de um piloto que caísse em alto mar e avaliar técnicas de reaquecimento do corpo; exposição de prisioneiros ao gás fosgênio, para teste de antígenos; infecção com agentes patógenos, para avaliar efeitos de preparados homeopáticos. ${ }^{2}$

Quanto ao segundo, trata-se de Convenção internacional celebrada no âmbito da Organização das Nações Unidas que, dentre outros aspectos, também tratou de dar, no ano de 1966, uma resposta às experiências levadas a cabo nos campos de concentração nazistas, por médicos pesquisadores ${ }^{3}$ e que contemplou, no art. $7^{\circ}$ do Pacto Internacional de Direito Civis e Políticos, a proibição de que uma pessoa seja submetida a uma experimentação médica ou científica sem o seu livre consentimento.

Já no que se refere às Organizações de caráter não governamental, cabe referir que em 1964 a Associação Médica Mundial (AMM) exarou a Declaração de Helsique, aportando um conjunto de princípios éticos a observar relativamente às pesquisas experimentais na pessoa humana, documento alterado posteriormente, em várias oportunidades. No ano de 2008, aconteceu a sexta revisão da Declaração de Helsinque (2008), quando foram inseridas duas novas temáticas até então inexploradas nas versões anteriores, quais sejam, a previsão de consentimento informado específico ${ }^{4}$ para que se proceda ao armazenamento e reutilização de materiais humanos em outras pesquisas, admitindo-se a possibilidade de que os comitês de ética possam considerar e aprovar uma investigação com esses biobancos sem o instrumento de consentimento, se for impossível ou impraticável requerê-lo ou também se se constituir em ameaça à própria validade do estudo e, outro ponto inovador, a necessidade de inscrição (ou registro) dos ensaios clínicos em uma base de dados de acesso público.

Outra organização que também tem se preocupado especificamente com essa problemática é o CIOMS (Conselho para Organizações Internacionais de Ciências Médicas), entidade que tem contribuído na elaboração de normas éticas internacionais sobre o tema, primeiramente, exarando, em 1982, as Diretrizes Éticas Internacionais para a Pesquisa Biomédica Envolvendo Humanos, revisadas posteriormente no ano de 1993 e em 2002. ${ }^{5}$ Entraram também em cena, no CIOMS, as Diretrizes Internacionais para a Revisão Ética dos Estudos Epidemiológicos, revisadas em 2009. Embora abordem, em síntese, o mesmo conteúdo, a segunda está mais voltada às pesquisas epidemiológicas, ou seja, às pesquisas na área da saúde em um nível mais macro, para a melhoria da saúde dos indivíduos, grupos e populações. 
Em relação às organizações de caráter não governamental, sustenta-se que:

No entanto, estas organizações têm um papel de liderança no desenvolvimento da ética médica e da bioética, pois de seu seio emanam normas internacionais, que exercem uma influência inegável como princípios inspiradores e orientadores da atividade dos Comitês Nacionais de Bioética, e em particular - através de seus documentos de caráter ético e seus $<$ guias de boa prática clínica $>$ - na atividade dos comitês de ética hospitalares e de ensaios clínicos. ${ }^{6.7}$

Relativamente a este tema em âmbito nacional, os instrumentos foram, para a classe médica, o Código de Ética Médica, consubstanciado na Resolução do Conselho Federal de Medicina no 1.246/1988. Este código de ética (da e para a) classe médica foi revogado e, desde 2010, está em vigor o novo código (Resolução no 1.931/2009).

Já no que diz com a autoridade estatal, foram exaradas Resoluções do Conselho Nacional de Saúde, órgão colegiado vinculado ao Ministério da Saúde. Primeiramente, em 1988 (Resolução CNS 01/1988), o referido órgão regulou as pesquisas com seres humanos na área da saúde. ${ }^{8}$ Posteriormente, em 1996 (Resolução CNS 196/1996), a pesquisa envolvendo seres humanos, modelo revisado em 2012 (Resolução CNS 466/2012). Acrescente-se, ainda que foram implementados sistemas de informação. ${ }^{9}$

A Resolução CNS no 466 foi aprovada em 12 de dezembro de 2012 pelo Conselho Nacional de Saúde, Enfatize-se, portanto, que o modelo regulatório brasileiro está estreitamente vinculado ao modelo do Sistema Único de Saúde (SUS), que prevê o controle social e a participação da comunidade como princípios norteadores.

No contexto evolutivo de 1996 para 2012, o Conselho Nacional de Saúde, inclusive, promoveu uma consulta pública (via site) no ano de 2011, para revisão, tendo recebido várias propostas. Advirta-se, por oportuno, que não é objeto do presente artigo analisar o teor dessas propostas, e nem mesmo perquirir se as contribuições ofertadas foram (ou não) efetivamente consideradas quando do processo revisório. Além dessa consulta pública, foram também realizados seminários temáticos no ENCEP (Encontro Nacional dos Comitês de Ética em Pesquisa), para manifestação e participação ativa dos componentes desses comitês institucionais, o que sem dúvida desnuda uma evidência: a necessidade imperiosa de expandir o debate.

No plano constitucional, cabe relembrar que a Constituição Brasileira trouxe um conjunto afirmativo de direitos fundamentais. Dentre esses direitos, restou expressamente consagrado o direito fundamental à saúde. ${ }^{10} \mathrm{O}$ direito à saúde, previsto através de um sistema único, é fruto de um vasto processo de articulação social, política e partidária das propostas de reforma sanitária defendidas e apresentadas pelos movimentos sociais durante a Assembleia Nacional Constituinte. É um sistema público nacional, baseado no princípio da universali- 
dade. ${ }^{11}$ Possui como diretrizes a descentralização, a integralidade do atendimento e a participação da comunidade, por meio do controle social.

No plano da legislação infraconstitucional, as duas grandes instâncias de deliberação previstas em lei são aquelas constantes na Lei 8.080/90 e na Lei 8.142/90, ou seja, as conferências e os conselhos de saúde, nas três esferas da federação brasileira. Ademais, se efetivamente há que fomentar o debate dentro do modelo SUS, há que provocá-lo também perante os mais de 5.000 conselhos de saúde já constituídos no Brasil, na esfera estadual e na esfera municipal (ver anexo). Considerando que as pesquisas não são exclusivamente realizadas em âmbito nacional, mas também em âmbito estadual e municipal, fundamental é saber se essa discussão ocorreu, de fato, nessas instâncias de deliberação legalmente constituídas e, se ocorreu, qual a sua extensão.

Como o modelo participativo concebido para o SUS foi pautado na participação comunitária (configurada pelo controle social por meio dos conselhos de saúde), o problema do presente artigo consiste em saber se com relação à Resolução no 466/2012, elaborada pelo Conselho Nacional de Saúde (que aprovou as diretrizes e normas regulamentadoras de pesquisas envolvendo seres humanos no Brasil), aconteceu a verticalização da discussão, como em outros temas vinculados ao SUS. O objetivo, portanto, é verificar se em relação ao que foi regulado no Brasil no que diz respeito à pesquisa envolvendo seres humanos, em especial a vigente Resolução CNS 466/2012, houve, ou não, participação do controle social em sua discussão por meio das instâncias colegiadas previstas mais especificamente na Lei no 8.142/90 (as conferências e os conselhos de saúde) e traçar os contornos dessa discussão, no período compreendido entre os anos de 1996 e 2012.

No plano metodológico, cumpre esclarecer, inicialmente, a razão do referido marco temporal, que considerou os seguintes referenciais: primeiro, a resolução anteriormente vigente (do ano de 1996), que estabeleceu as normas e diretrizes regulamentadoras para as pesquisas envolvendo seres humanos; segundo, a nova resolução atualmente em vigor (do ano de 2012), que substituiu a resolução anterior. Sendo assim, buscou-se identificar se constou algum registro que demonstrasse a intenção de realizar essa discussão, de forma específica.

A metodologia da pesquisa foi preponderantemente documental, com pesquisas nas atas das reuniões e assembleias ordinárias e extraordinárias do Conselho Municipal de Saúde de Canoas/RS e documentos referentes às Conferências Municipais de Saúde do mesmo Município, ocorridas entre 1996 e 2012 e que foram localizados para pesquisa. Cabe explicitar também a escolha do Município de Canoas, que se deve ao vínculo institucional dos pesquisadores, pesquisa que posteriormente será ampliada para outros entes da federação.

Agregou-se, ainda, a análise dos relatórios das Conferências Nacionais de Saúde disponibilizados no site do Conselho Nacional de Saúde, de forma a destacar, exemplificativamente, alguns traços de discussão existentes nos relatórios finais das conferências nacionais de saúde realizadas no mesmo período. 


\section{CONTROLE SOCIAL NA SAÚDE: O PAPEL DAS CONFERÊNCIAS E DOS CONSELHOS DE SAÚDE}

A participação da população, no que tange à saúde, não iniciou com o Sistema Único de Saúde (SUS). Anteriormente existiam os conselhos comunitários, os conselhos populares e os conselhos administrativos, que constituíam uma forma de participação já existente nas décadas de 1970 e 1980, muito embora possuíssem uma relação clientelista entre Estado e sociedade, não envolvimento institucional e ausência de poder para influir no desenho das políticas públicas. ${ }^{12}$ Ainda que naquele contexto essa participação fosse evidentemente limitada, cabe referir a seguinte lição:

A participação social como elemento estruturante do sistema nacional de saúde esteve presente desde o início da proposta do movimento da Reforma Sanitária, que, já na década de 1970, compreendia como indissociáveis as lutas contra a ditadura militar, pela democratização do poder público e pela garantia da saúde como direito do cidadão e dever do Estado. ${ }^{13}$

Foi em 1986, no Relatório Final da 8a Conferência Nacional de Saúde (CNS) que foi proposta uma nova e completa concepção das políticas de saúde em vigor na época. Esta conferência trouxe contribuições ímpares. Além de propor a constituição de um novo conselho de saúde, propôs o seguinte (tema 2, Reformulação do Sistema Nacional de Saúde, item 25):

Deverão também ser formados Conselhos de Saúde em níveis local, municipal, regional e estadual, compostos de representantes eleitos pela comunidade (usuários e prestadores de serviço), que permitam a participação plena da sociedade no planejamento, execução e fiscalização dos programas de saúde[.... $]^{14}$

No período pós Constituição Federal de 1988, ganhou força a categoria da participação social, dando vigor à concepção de participação como cidadania. Cabe lembrar que, inicialmente, na regulamentação do SUS que ocorreu com a Lei no 8.080, de 19 de setembro de 1990, os dispositivos aprovados no Projeto de Lei no 50/90 (no 3.110/89, na origem), que previam a participação popular, foram vetados pelo então presidente Fernando Collor de Mello. Isso exigiu um novo processo de mobilização e um novo processo de articulação que acabou culminando na Lei no 8.142, de 28 de dezembro de 1990.

Assim, a Lei no 8.142/1990 reproduziu o texto original e institucionalizou duas instâncias colegiadas de participação em cada esfera de governo: as conferências de saúde e os conselhos de saúde. Há previsão de que a Conferência de Saúde reunir-se-á a cada quatro anos, com a representação dos vários seguimentos sociais para avaliar a situação de saúde e propor as diretrizes para a formulação da política de saúde nos níveis correspondentes. Quanto aos conselhos de saúde, a mesma Lei nos diz que em caráter permanente e deliberativo, o conselho é órgão colegiado composto por representantes do governo, prestadores de serviço, profissionais de saúde e usuários, que atua na formulação de estratégias e no 
controle da execução da política de saúde na instância correspondente, inclusive nos aspectos econômicos e financeiros, cujas decisões são homologadas pelo chefe do poder legalmente constituído em cada esfera do governo. Cabe referir, nesse contexto, o seguinte posicionamento:

A norma legal estabeleceu um fluxo decisório e operacional no qual as conferências propõem diretrizes para a formulação de políticas a partir da avaliação da situação de saúde, os conselhos formulam estratégias e controlam a execução das políticas, e as instâncias executivas (Ministério da Saúde, secretarias estaduais e municipais de saúde) implementam as políticas e homologam as deliberações dos conselhos. Os elementos que integram esse fluxo decisório guardam em si importantes diferenças tanto no número quanto na sua representatividade. ${ }^{15}$

Especificamente quanto à atuação dos Conselhos de Saúde, sustenta-se que há um considerável avanço relativamente ao controle das ações governamentais, pelos cidadãos assim como "mudança na forma de interferir - deslocando o clientelismo e fisiologismo tradicionais - e ao processo pedagógico de aprendizado do exercício do poder político". ${ }^{16} \mathrm{Com}$ relação às Conferências de Saúde, ${ }^{17}$ há "um avanço no processo de participação social, um sistema participativo com grande capilaridade, valor pedagógico e contribuições para a cultura democrática participativa”.

Destaquem-se, na mesma linha, os papéis distintos e complementares desempenhados pelas Conferências de Saúde e pelos Conselhos de Saúde:

Enquanto os conselhos de saúde têm a função de formular estratégias e controlar a execução das políticas, as conferências surgem como uma das arenas nas quais a participação social se antecipa à formulação de políticas, pois se volta para desenhar os princípios, diretrizes e pressupostos que devem orientar todo o processo de formulação de políticas de saúde no período seguinte. As conferências são, desse modo, espaço público de deliberação coletiva sobre as diretrizes que devem guiar a estruturação e condução do SUS, sendo que nelas o princípio da participação da comunidade assume explicitamente um caráter decisório acerca da configuração do sistema. ${ }^{18}$

\section{A DISCUSSÃO DO TEMA NO MUNICÍPIO DE CANOAS/RS (CONSE- LHO MUNICIPAL DE SAÚDE E CONFERÊNCIAS MUNICIPAIS DE SAUUDE) E CONFERÊNCIAS NACIONAIS DE SAÚDE}

Embora, como já visto, o processo de revisão da Resolução n 196/1996 e elaboração da Resolução no 466/2012 tenha passado por um processo de consulta pública (que não constitui objeto deste estudo), pelas razões já explicitadas, buscamos verificar se essa discussão se deu no âmbito do Conselho Municipal de Saúde (CMS) do Município de Canoas/RS e, se positivo, qual o alcance dessa discussão. 
Essa pesquisa limitou-se aos anos de 1996 a 2012 (período entre o início de vigor da Resolução no 196/1996 e entrada em vigor da Resolução o 466/2012, ou seja, momento que poderia compreender a revisão da Resolução no 196/1996 e elaboração da Resolução no 466/2012). Com o intuito de verificar se o tema constituiu pauta específica nas reuniões e assembleia do Conselho, foram utilizadas as seguintes expressões como palavras-chave de pesquisa, nas pautas constantes nas atas do Conselho Municipal de Saúde: "pesquisa com seres humanos", "pesquisa envolvendo seres humanos", "CONEP", "controle social da pesquisa", "Resolução no 196/1996”, e, "Resolução no 466/2012”.

Como a primeira ata do conselho é da data de 9 de outubro de 1997, a pesquisa iniciou nesta data e finalizou em 10 de dezembro de 2012 (última reunião do ano). Ao todo foram pesquisadas 324 (trezentas e vinte e quatro) atas de assembleias e reuniões ordinárias e extraordinárias do Conselho Municipal de Saúde do Município de Canoas no período compreendido entre 9 de outubro de 1997 a 10 de dezembro de 2012 (ver apêndice). Entre os documentos pesquisados, nenhum apresentou como ponto de pauta específico discussão que tivesse como objeto construir contribuições para revisão da Resolução no 196/1996 ou a elaboração da Resolução n 466/2012.

A pesquisa, portanto, evidenciou que no âmbito do Município de Canoas/ RS não houve discussão específica, nessa instância colegiada de participação prevista na Lei no 8.142/90, referentemente à discussão sobre a revisão da Resolução do Conselho Nacional de Saúde que posteriormente aprovaria as novas diretrizes e normas regulamentadoras de pesquisas envolvendo seres humanos para o Brasil.

Embora não se tenha localizado documento que comprovasse a discussão junto ao Conselho Municipal de Saúde do Município de Canoas/RS, esse fato não demonstra necessariamente que a discussão não tenha ocorrido em outros municípios. Isso será objeto de pesquisas futuras. É importante destacar que no Município de Canoas/RS não se deu essa verticalidade nas discussões. É natural, até pelo seu papel, que os conselhos municipais foquem suas discussões aos assuntos locais, reservando debates que tenham um caráter mais estadual e/ ou nacional normalmente para as conferências de saúde, que, além de ser um momento de discussão coletiva, elegem delegados para as etapas estaduais e, por conseqüência, para a etapa nacional das conferências.

As discussões das conferências, por sua vez, são sobre temas diversos e em nível de diretrizes gerais, não sendo realizadas discussões com o intuito específico de elaborar textos normativos na sua integralidade, apenas as pautas gerais. Sendo assim, buscou-se identificar se nas Conferências Municipais de Saúde do Município de Canoas/RS houve discussão específica sobre o tema no mesmo período (1996 a 2012).

Em relação às conferências, o material disponível para consulta junto ao Conselho Municipal de Saúde limitou-se aos anos de 2003, ${ }^{19} 2007$ e 2011, ${ }^{20}$ anos em que foram realizadas respectivamente a $3^{\mathrm{a}}, 4^{\mathrm{a}}$ e $5^{\mathrm{a}}$ Conferência Municipal de 
Saúde. Da mesma forma, não foi encontrada no material pesquisado discussão sobre o tema.

Como a análise se deu em apenas um Município (Canoas/RS), e, como as Conferências Nacionais são expressões das discussões realizadas nos demais conselhos (pois são precedidas de etapas estaduais e municipais), avançou-se no sentido de buscar identificar até que ponto as Conferências Nacionais trouxeram a temática no bojo de discussões realizadas. Assim, foram analisados os relatórios das Conferências Nacionais de Saúde disponibilizados no site do Conselho Nacional de Saúde (CNS).

Ao analisarmos os relatórios finais da 10 $11^{\mathrm{a}}, 12^{\mathrm{a}}, 13^{\mathrm{a}}$ e $14^{\mathrm{a}}$ conferências, ocorridas respectivamente nos anos de 1996, 2000, 2003, 2007 e 2011, não se logrou obter resultados que evidenciassem qualquer discussão mais específica do tema (pesquisa envolvendo seres humanos e sua regulação). Embora não tenha sido encontrado um eixo específico de discussão que retratasse qualquer intenção de construção de proposição de revisão/elaboração das resoluções do CNS n 196/1996 e n 466/2012, foram encontrados, exemplificativamente, alguns textos esparsos.

Como há alguma vinculação, ainda que tangencialmente, com a temática da pesquisa, eis os achados. Primeiro, no Relatório Final da 11 a Conferência Nacional de Saúde, realizada no ano 2000: a) "Criar, no prazo de seis meses, a partir dos Conselhos Estaduais de Saúde, a Comissão de Ética dos Institutos de Pesquisa em Saúde, e fiscalizá-los periodicamente, para que cumpram eticamente a função" ${ }^{21}$; b) "Criar uma rede de Comitês de Ética e Segurança das Informações, com a participação direta de representantes dos usuários do SUS e da sociedade em geral. Com isso, estabelecer um espaço de interlocução com a sociedade civil, articulando iniciativas entre vários setores, tais como Ministério Público, Ministério e Secretarias da Saúde, sociedades científicas, comitês de Ética em Pesquisa Envolvendo Seres Humanos, entre outros". ${ }^{22}$

Segundo, no Relatório Final da 12a Conferência Nacional de Saúde, realizada no ano 2003: a) "Garantir como uma das prioridades do Plano Nacional de Saúde a pesquisa em saúde com alocação de recursos específicos e padrões éticos definidos" ${ }^{23}$; b) "Estabelecer a relevância social e o mérito técnico-científico como critérios relevantes de análise dos projetos de pesquisa pelos órgãos de fomento" $;{ }^{24}$ c) "Incentivar, por parte das três esferas de governo, a aplicabilidade das pesquisas em saúde criando mecanismos de controle de sua eficácia"; ${ }^{25} d$ ) "Fortalecer as Comissões de Ética em Pesquisa (CEP) no controle social das pesquisas em seres humanos, priorizando os princípios do SUS; ${ }^{26}$ e) "Criar a Comissão Nacional e comissões estaduais de bioética visando ao debate das questões éticas em conflito na sociedade, incluindo as referentes ao campo da Saúde"; ${ }^{27}$ f) "Criar a comissão de bioética nos serviços de saúde dos estados e municípios, quando necessário, para avaliação dos protocolos de pesquisas que envolvam seres humanos e discussão de aspectos éticos envolvidos na atenção à saúde" ${ }^{28} \mathrm{~g}$ ) "Opor-se à clonagem de seres humanos, em qualquer circunstância, 
admitindo somente as pesquisas com clonagem de células ou tecidos humanos com finalidades terapêuticas". ${ }^{29}$

Terceiro, no Relatório Final da 13a Conferência Nacional de Saúde, realizada no ano 2007: a) "Assegurar o financiamento tripartite à informação científica e tecnológica, bem como o desenvolvimento de estudos e pesquisas de interesse para o SUS, em estrita observância à Resolução CNS no 196/96"; 30 b) "Que o Conselho Nacional de Saúde reveja a Resolução n" 240/97, referente à participação de usuários nos Comitês de Ética em Pesquisa (CEPs), de modo a torná-la objetiva e efetiva, exigindo a criação de Comissão de Ética e a implantação de CEPs em toda e qualquer instituição pública ou privada que desenvolva pesquisa com seres humanos, fortalecendo o controle social com a participação de representantes da sociedade civil". ${ }^{31}$

Quarto, no Relatório Final da 14a Conferência Nacional de Saúde, realizada no ano 2011: a) "Realização e divulgação dos resultados das pesquisas pelas Instituições de Ensino Superior visando ao tratamento, à cura, à qualidade de vida das pessoas com doença falciforme"; ${ }^{32}$ b) "Que a sociedade civil tenha a sua participação representativa garantida nos espaços de discussão e decisão sobre medicamentos, seus efeitos, pesquisa e disponibilidade na rede pública visando à atualização dos protocolos clínicos, como forma de conhecimento para proporcionar segurança e qualidade"; ${ }^{33}$ c) "Incentivo às pesquisas científicas das doenças reumáticas”. ${ }^{34}$

Esclareça-se o fato de que mesmo o material encontrado relacionado ao tema junto aos relatórios finais das conferências nacionais de saúde, embora pudessem ser considerados como contribuições, são colaborações tão esparsas que não possuem o objetivo de construir texto normativo e nem mesmo contribuir para esse debate regulatório específico, relacionado à pesquisa com seres humanos.

Como afirmado anteriormente, as discussões das conferências são de temas diversos e para pautar as diretrizes gerais, não tendo o objetivo específico de elaborar textos normativos pontuais de forma integral. Embora nem sempre se transformem em ações, em geral influenciam a política de saúde de forma muito expressiva, como assim afirmado:

Não tendo um caráter deliberativo e funcionando mais como um mecanismo de ausculta da sociedade, os debates das conferências nem sempre se desdobraram em ações do Executivo. Entretanto, é inegável a influência desses fóruns em processos como o da intensa municipalização a partir da 9a CNS, ou o do crescimento da importância do controle social a partir dos conselhos de Saúde depois da $10^{\text {a }} \mathrm{CNS} .{ }^{35}$

Veja-se, a propósito, a pesquisa do Laboratório de Planejamento Participativo em Saúde da Universidade de Brasília - Lappas/UnB, sobre 25 anos de conferências de Saúde democráticas e participativas, a partir de uma revisão 
sistemática de literatura e da análise de regulamentos internos e relatórios finais, indicando o crescimento do número de deliberações:

Se, por um lado, o crescimento expressa a complexificação do sistema de Saúde e a pluralidade de interesses presentes nesse fórum, revela, por outro, um universo extremamente fragmentado, com possíveis perdas de substância das propostas aprovadas e a inexequibilidade de tantas resoluções. [ ...] As deliberações abrangem praticamente todo o espectro de ações implementadas pelo SUS. Mas o papel das diretrizes expressas pelas conferências é tornar claros os objetivos que devem ser alcançados pela política de saúde. ${ }^{36}$

É certo que quanto maior a quantidade de propostas, maior a dificuldade de efetivação integral das diretrizes construídas nas conferências, e também nos conselhos de saúde. De qualquer forma, há um avanço ao longo da história no que tange a esses (novos) espaços de deliberação, que se aprimoram ao longo do tempo.

\section{CONSIDERAÇÕES FINAIS}

Há uma importância significativa do controle social no que diz respeito à institucionalização do direito fundamental à saúde, consagrado na Constituição Federal brasileira. Da mesma forma, há um avanço desde o reconhecimento desse direito como direito fundamental até sua consolidação e construção cotidiana de um direito social "novo", ao menos na sua concepção. Além disso, o processo de participação também tem vivido uma evolução, seja da sua organização, seja da sua capacidade quantitativa de produção de proposições.

No entanto, como visto, há uma necessidade de organização dessa produção em especial pela necessidade de priorização e monitoramento da sua efetivação. Do contrário, as construções coletivas podem tornar-se banalizadas na medida em que se transformam em instrumentos repetitivos e de soma de demandas e diretrizes ao que até então vem sendo construído de forma repetitiva, muito embora, como demonstrado, tem influenciado a política de saúde.

Em especial no que tange à discussão relacionada à revisão da Resolução no 196/1996 ou à elaboração da "nova" resolução no 466/2012, a pesquisa documental realizada quanto ao Município de Canoas/RS permite afirmar que neste Município a discussão não aconteceu, o que pode ser um indicativo de que essa discussão também não foi verticalizada junto a outros conselhos municipais, órgãos que, ao menos em tese, estão mais próximos da concretização da matéria disciplinada, no mínimo para considerar uma participação mais ampla e efetiva da sociedade civil organizada, através dos conselhos de saúde e das conferências de saúde, nas três esferas da federação.

Considerando que se trata do modelo SUS, parece no mínimo salutar que, para além de consulta pública sobre o tema, via internet (sem dúvida importante, já que viabiliza a participação de qualquer cidadão), sejam resgatados 
os papéis dos demais entes da federação nesse contexto, já que esse modelo não se constrói de cima para baixo e sim sob a idéia de federalismo cooperativo na área da saúde, e com uma marcante e distintiva nota de participação social por meio dos conselhos de saúde e conferências de saúde em âmbito federal, estadual e municipal. Isso tanto para a normatização (ou pelo menos a discussão acerca de quais devam ser esses parâmetros gerais), quanto para a fiscalização, o que não apenas reforça o modelo do controle social como também confere maior transparência no que diz respeito aos processos decisórios sobre temas de tão grande relevância para a sociedade.

Informe-se, a propósito, que a Comissão Nacional de Ética em Pesquisa (CONEP), criada pelo Conselho Nacional de Saúde, estipulou o dia 04 de setembro de 2015 como sendo o encerramento do período da "Consulta à sociedade" a respeito do conteúdo de minuta de resolução complementar, a ser expedida pelo Conselho Nacional de Saúde, que regulamentará "As Especificidades Éticas das Pesquisas nas Ciências Sociais e Humanas e de outras que se utilizam de metodologias próprias dessas áreas".

Anote-se, ademais, que o órgão fundamentou o seu agir nas duas grandes declarações de direitos da ONU e da OEA do ano de 1948 (Declaração Universal dos Direitos Humanos e a Declaração Interamericana de Direitos e Deveres Humanos), incompreensível nesse ponto, já nenhuma dessas declarações se preocupou com essa temática específica, reconhecendo, isso sim, a liberdade de investigação científica. A autoridade apontou ainda como fundamentação do seu agir duas normas internas já referidas neste estudo, a Resolução CNS 196/1996 (quando o Conselho Nacional de Saúde criou a CONEP e o novo sistema CEP/CONEP) e a Resolução CNS 466/12 (em que o mesmo órgão estabeleceu que as pesquisas nas áreas das Ciências Humanas e Sociais têm especificidades). Por tais razões, resolveu, então, estabelecer normas de organização e procedimento para as Pesquisas nas Ciências Sociais e Humanas, excluindo desse âmbito regulatório (pelo menos a considerar o teor da minuta sob consulta pública) apenas as pesquisas de opinião pública (com participantes não identificados), as pesquisas que utilizem informações de acesso público ou de domínio público; as pesquisas censitárias do IBGE (e equivalentes), as pesquisas com bancos de dados (sem possibilidade de identificação individual) e, por derradeiro, as pesquisas realizadas exclusivamente com artigos científicos para revisão da literatura científica.

Abstraídas as questões relativas às competências constitucionais e atribuições dos órgãos públicos, pontos que não constituem objeto deste estudo, observe-se outro aspecto, o do meio eleito para se fazer essa consulta pública: via e-mail (conep.csh@saude.gov.br). Ou seja, não foi utilizado o portal governamental denominado Consulta Pública. Isso significa que não é possível saber quem participou da consulta, qual o teor dessa participação, nem mesmo saber quais contribuições foram ou não efetivas para o debate. Em síntese, inexistem mecanismos garantidores de transparência. 
Diante do importante avanço na consolidação do direito fundamental à saúde e do processo de aprofundamento da participação social através dos instrumentos instituídos pela Lei no 8.142/1990 (conselhos e conferências de saúde), e, diante da importância de regulação desse tema que é a pesquisa com seres humanos, e, mais ainda, a falta de instrumento legal que legitime expressamente a possibilidade do Conselho Nacional de Saúde normatizar matérias outras que não a saúde, fundamental seria que o próprio órgão fomentasse uma discussão ampla sobre o tema em nível nacional, aproveitando a estrutura e os mecanismos de participação social já existentes no Brasil.

Essa iniciativa consolidaria os avanços já elencados (do direito à saúde e da participação social) e, sobretudo, abriria uma ampla e efetiva discussão, oportunizando uma maior participação dos cidadãos e da sociedade civil organizada, não se limitando apenas aos comitês de ética, nem tão pouco à CONEP e ao Conselho Nacional de Saúde.

\section{REFERÊNCIAS}

BARROSO, Luís Roberto. Da Falta de Efetividade à Judicialização Excessiva: Direito à Saúde, Fornecimento Gratuito de Medicamentos e Parâmetros para a Atuação Judicial. In: SOUZA NETO, Cláudio Pereira de; SARMENTO, Daniel (Coords.). Direitos Sociais: Fundamentos, Judicialização e Direitos Sociais em Espécie. 2. tir. Rio de Janeiro: Editota Lúmen Júris, 2010.

BRASIL. Lei $\mathbf{n}^{\circ} \mathbf{8 . 1 4 2}$, de 28 de dezembro de 1990. Dispõe sobre a participação da comunidade na gestão do Sistema Único de Saúde (SUS) e sobre as transferências intergovernamentais de recursos financeiros na área da saúde e dá outras providências. Disponível em: <http://www.planalto.gov.br/ccivil_03/leis/18142. htm>. Acesso em: 28 abr. 2015.

. Veto Parcial ao Projeto de Lei no 50, de 1990 (n 3.110/89, na origem). Disponível em: <http://www.planalto.gov.br/ccivil_03/leis/Mensagem_Veto/ anterior_98/Vep680-L8080-90.pdf>. Acesso em: 27 abr. 2015.

. Conselho Nacional de Saúde. Aprova diretrizes e regulamentadoras de pesquisas envolvendo seres humanos, através da Resolução n 196, de 1996. Disponível em: 〈http://www.bioetica.ufrgs.br/res19696.htm>. Acesso em: 29 abr. 2015.

. Aprova as diretrizes e normas regulamentadoras de pesquisas envolvendo seres humanos, através da Resolução no 466, de 12 de dezembro de 2012. Disponível em <http:// http://conselho.saude.gov.br/resolucoes/2012/ Reso466.pdf> Acesso em: 8 mai. 2015.

. Consulta Pública. Disponível em: <http://200.214.130.94/CONSULTAPUBLICA/INDEX.PHP?MODULO=DISPLAY\&SUB=DSP_CONSULTA. >. Acesso em: 2 set. 2015. 
CHAVES, Antônio. Pesquisas em seres humanos. Revista de Informação Legislativa, Senado Federal, n. 108, 1990.

CIOMS. Diretrizes Éticas Internacionais para a Pesquisa Biomédica Envolvendo Humanos. Council for International Organizations of Medical Sciences Disponível em: <http://www.cioms.ch/publications/guidelines/guidelines_nov_2002_ blurb.htm>. Acesso em: 23 mai. 2011.

. Diretrizes Internacionais para a Revisão Ética dos Estudos Epidemiológicos. Council for International Organizations of Medical Sciences. Genebra, 2009. Disponível em: <http://www.cioms.ch/frame_ethical_guidelines_2009.htm>. Acesso em: 23 mai. 2011.

CONFERÊNCIA MUNICIPAL DE SAÚDE, n. 3, 2003, Canoas, RS. Anais. Canoas, 2003.

CONFERÊNCIA NACIONAL DE SAÚDE. n. 8, 1986, Brasília, DF. Relatório Final. Brasília, 1986. Disponível em: <http://conselho.saude.gov.br/biblioteca/ relatorios/relatorio_8.pdf>. Acesso em: 27 abr. 2015.

n. 10, 1996, Brasília, DF. Relatório Final. Brasília, 1998. Disponível em: 〈http://conselho.saude.gov.br/biblioteca/Relatorios/relatorio_10.pdf〉. Acesso em: 21 mai. 2015.

. n. 11, 2000, Brasília, DF. Relatório Final. Brasília, 2002. Disponível em: <http://conselho.saude.gov.br/biblioteca/Relatorios/relatorio_11.pdf $>$. Acesso em: 21 mai. 2015.

n. 12, 2003, Brasília, DF. Relatório Final. Brasília, 2004. Disponível em: <http://conselho.saude.gov.br/biblioteca/Relatorios/relatorio_12.pdf $>$. Acesso em: 21 mai. 2015.

. n. 13, 2007, Brasília, DF. Relatório Final. Brasília, 2008. Disponível em: <http://conselho.saude.gov.br/biblioteca/Relatorios/13cns_M.pdf>. Acesso em: 21 mai. 2015.

. n. 14, 2011, Brasília, DF. Relatório Final. Brasília, 2012. Disponível em: <http://conselho.saude.gov.br/biblioteca/Relatorios/img/14_cns\%20 relatorio_final.pdf $>$. Acesso em: 21 mai. 2015.

- Questionário pare a a 15 Conferencia [mensagem pessoal]. Mensagem recebida por: <cmscanoas@gmail.com> em 14 abril 2015.

DECLARACION DE HELSINKI DE LA ASOCIACION MEDICA MUNDIAL. Principios éticos para las investigaciones médicas en seres humanos. 59a Asamblea General, Seúl, Corea, octubre 2008. WMA. Disponível em: <http://www.wma. net/es/30publications/10policies/b3/17c_es.pdf>. Acesso em: 01 abr. 2011.

DOMINGUEZ, Bruno. As Vozes do Brasil. RADIS, Rio de Janeiro, n.144, p. $11-17$, set. 2014 . 
ESCOREL, Sarah; MOREIRA, Marcelo Rasga. Participação Social. In: GIOVANELLA, Lígia; ESCOREL, Sarah; LOBATO, Lenaura de Vaconcelos Costa et al (Org.). Política e Sistema de Saúde no Brasil. Rio de Janeiro: Editora FIOCRUZ, 2012. P. 853-883.

FERNÁNDEZ, Juan Antonio Díez. Los comités nacionales de bioética: Legislación internacional y regulación en la nueva ley sobre investigación biomédica. Granada: Editorial Comares, 2007.

FIGUEIREDO, Mariana Filchtiner. Direito fundamental à saúde: parâmetros para sua eficácia e efetividade. Porto Alegre: Livraria do Advogado Editora, 2007.

GIOVANELLA, Lígia; ESCOREL, Sarah; LOBATO, Lenaura de Vaconcelos Costa et al (Orgs.). Política e Sistema de Saúde no Brasil. Rio de Janeiro: Editora FIOCRUZ, 2012.

GUIZARDI, Francini Lube et al. Participação da comunidade em espaços públicos de saúde: uma análise das conferências nacionais de saúde. Physis [online], 2004, v. 14, n. 1, pp. 15-39. Disponível em: < http://www.scielo.br/pdf/physis/ v14n1/v14n1a03.pdf>. Acesso em: 21 mai. 2015.

LUNA, Florencia. Investigación. In: LUNA, Florencia; SALLES, Arleen L. F. (Orgs.). Bioética: nuevas reflexiones sobre debates clásicos. Buenos Aires: Fondo de Cultura Económica, 2008.

PETTERLE, Selma Rodrigues. Liberdade de pesquisar, pesquisas clínicas e outras pesquisas científicas de risco envolvendo seres humanos: uma proposta de reformulação do atual sistema de controle implementado pelo Conselho Nacional de Saúde, à luz da Constituição Brasileira. 2012. 274 f. Tese (Doutorado em Direito) - Programa de Pós-Graduação em Direito, Pontifícia Universidade Católica do Rio Grande do Sul, Porto Ảlegre, 2012.

. A informação sobre pesquisas envolvendo seres humanos no Brasil: do SISNEP à Plataforma Brasil. In: MACHADO, Ednilson Donisete, CATTONI DE OLIVEIRA, Marcelo Andrade (Coord.). Direitos Fundamentais e Democracia I. Florianópolis : FUNJAB, 2013.

ROSENAU, Henning. Le conditions légales préalables requises pour les essais Clinique d'après la Declaration d'Helsinki révisée et la Convention Européenne sur les Droits de l'Homme et la Biomédecine. Journal International de Bioéthique. Nouvelles pratiques, nouvelles éthique de la recherche biomédical? 1.er partie. v. 15, n. 1, Mars. 2004.

RUIZ, Juana María Gil. Investigación médica en seres humanos. In: VALLEJO, Pilar Rivas, VALVERDE, María D. García (Org.). Derecho y Medicina. Cuestiones jurídicas para profesionales de la salud. Cizur Menor: Thomson Reuters: Aranzadi, 2009. 
SARLET, Ingo Wolfgang. A eficácia dos direitos fundamentais: uma teoria geral dos direitos fundamentais na perspectiva constitucional. 10. ed. rev. atual e ampl. Porto Alegre: Livraria do Advogado, 2009.

. PETTERLE, Selma Rodrigues. Liberdade de pesquisa como direito humano e fundamental e seus limites: a pesquisa com seres humanos e os parâmetros protetivos estabelecidos pelo direito internacional e sua recepção no Brasil. Revista Espaço Jurídico, v. 15, 2014. 
APÊNDICE - Tabela com a relação das atas pesquisadas, relativas às reuniões e assembleias ordinárias e extraordinárias do Conselho Municipal de Saúde do Município de Canoas/RS (1997 - 2012)

\begin{tabular}{|c|c|c|c|c|c|c|}
\hline \multirow{3}{*}{1997} & Ata & 1,2 & 1 & PRÉ-INSTALAC̣ÃO & 09 e $23 / 10$ & Não \\
\hline & Ata & 3 & 1 & INSTALAÇÃO & $14 / 11$ & Não \\
\hline & Ata & 4 & 1 & $\begin{array}{l}\text { ASSEMBLEIA GERAL EXTRA- } \\
\text { ORD. }\end{array}$ & $29 / 12$ & Não \\
\hline \multirow{14}{*}{1998} & Ata & 5,6 e 7 & 1 & $\begin{array}{l}\text { ASSEMBLEIA GERAL EXTRA- } \\
\text { ORD. }\end{array}$ & $12 / 01,09 / 02$ e $26 / 02$ & Não \\
\hline & Ata & 8 & 1 & $\begin{array}{l}\text { ASSEMBLEIA GERAL ORDI- } \\
\text { NÁRIA }\end{array}$ & 09/03 & Não \\
\hline & Ata & 9 & 1 & $\begin{array}{l}\text { ASSEMBLEIA GERAL EXTRA- } \\
\text { ORD. }\end{array}$ & $23 / 03$ & Não \\
\hline & Ata & 10,11 e 12 & 1 & $\begin{array}{l}\text { ASSEMBLEIA GERAL ORDI- } \\
\text { NÁRIA }\end{array}$ & $13 / 04,11 / 05,08 / 06$ & Não \\
\hline & Ata & 13 & 1 & $\begin{array}{l}\text { ASSEMBLEIA GERAL EXTRA- } \\
\text { ORD. }\end{array}$ & 06/07 & Não \\
\hline & Ata & 14 & 1 & $\begin{array}{l}\text { ASSEMBLEIA GERAL ORDI- } \\
\text { NÁRIA }\end{array}$ & $13 / 07$ & Não \\
\hline & Ata & $15,16,17$ & 1 & $\begin{array}{l}\text { ASSEMBLEIA GERAL EXTRA- } \\
\text { ORD. }\end{array}$ & $27 / 07,10 / 08,31 / 08$ & Não \\
\hline & Ata & 18 & 1 & $\begin{array}{l}\text { ASSEMBLEIA GERAL ORDI- } \\
\text { NÁRIA }\end{array}$ & $14 / 09$ & Não \\
\hline & Ata & 19 & 1 & $\begin{array}{l}\text { ASSEMBLEIA GERAL EXTRA- } \\
\text { ORD. }\end{array}$ & $13 / 10$ & Não \\
\hline & Ata & 20 & 1 & $\begin{array}{l}\text { ASSEMBLEIA GERAL ORDI- } \\
\text { NÁRIA }\end{array}$ & $19 / 10$ & Não \\
\hline & Ata & 21 & 1 & $\begin{array}{l}\text { ASSEMBLEIA GERAL EXTRA- } \\
\text { ORD. }\end{array}$ & $29 / 10$ & Não \\
\hline & Ata & 22 & 1 & $\begin{array}{l}\text { ASSEMBLEIA GERAL ORDI- } \\
\text { NÁRIA }\end{array}$ & $09 / 11$ & Não \\
\hline & Ata & 23 & 1 & $\begin{array}{l}\text { ASSEMBLEIA GERAL EXTRA- } \\
\text { ORD. }\end{array}$ & $16 / 11$ & Não \\
\hline & Ata & 24 & 1 & $\begin{array}{l}\text { ASSEMBLEIA GERAL ORDI- } \\
\text { NÁRIA }\end{array}$ & $14 / 12$ & Não \\
\hline \multirow{6}{*}{1999} & Ata & $25,26,27,28$ & 1 & $\begin{array}{l}\text { ASSEMBLEIA GERAL ORDI- } \\
\text { NÁRIA }\end{array}$ & $\begin{array}{l}11 / 01,08 / 02 \text { 08/03, } \\
12 / 04\end{array}$ & Não \\
\hline & Ata & 29 & 1 e 2 & $\begin{array}{l}\text { ASSEMBLEIA GERAL ORDI- } \\
\text { NÁRIA }\end{array}$ & $10 / 05$ & Não \\
\hline & Ata & $\begin{array}{l}30,31,32,33 \\
34,35\end{array}$ & 2 & $\begin{array}{l}\text { ASSEMBLEIA GERAL ORDI- } \\
\text { NÁRIA }\end{array}$ & $\begin{array}{l}14 / 06,12 / 07,09 / 08 \\
13 / 09,18 / 10,08 / 11\end{array}$ & Não \\
\hline & Ata & $36,37,38$ & 2 & $\begin{array}{l}\text { ASSEMBLEIA GERAL EXTRA- } \\
\text { ORD. }\end{array}$ & $18 / 11,22 / 11,22 / 11$ & Não \\
\hline & Ata & 39 & 2 & $\begin{array}{l}\text { ASSEMBLEIA GERAL ORDI- } \\
\text { NÁRIA }\end{array}$ & $13 / 12$ & Não \\
\hline & Ata & 40 & 2 & $\begin{array}{l}\text { ASSEMBLEIA GERAL EXTRA- } \\
\text { ORD. }\end{array}$ & $20 / 12$ & Não \\
\hline
\end{tabular}




\begin{tabular}{|c|c|c|c|c|c|c|}
\hline \multirow{16}{*}{2000} & Ata & $41,42,43,44$ & 2 & $\begin{array}{l}\text { ASSEMBLEIA GERAL ORDI- } \\
\text { NÁRIA }\end{array}$ & $\begin{array}{l}10 / 01,14 / 02,13 / 03, \\
10 / 04\end{array}$ & Não \\
\hline & Ata & 45 & 2 & $\begin{array}{l}\text { ASSEMBLEIA GERAL EXTRA- } \\
\text { ORD. }\end{array}$ & $24 / 04$ & Não \\
\hline & Ata & 46 & 2 e 3 & $\begin{array}{l}\text { ASSEMBLEIA GERAL ORDI- } \\
\text { NÁRIA }\end{array}$ & $08 / 05$ & Não \\
\hline & Ata & 47 & 3 & $\begin{array}{l}\text { ASSEMBLEIA GERAL EXTRA- } \\
\text { ORD. }\end{array}$ & $22 / 05$ & Não \\
\hline & Ata & 48,49 & 3 & $\begin{array}{l}\text { ASSEMBLEIA GERAL ORDI- } \\
\text { NÁRIA }\end{array}$ & $12 / 06,10 / 07$ & Não \\
\hline & Ata & 50 & 3 & $\begin{array}{l}\text { ASSEMBLEIA GERAL EXTRA- } \\
\text { ORD. }\end{array}$ & $24 / 07$ & Não \\
\hline & Ata & 51 & 3 & $\begin{array}{l}\text { ASSEMBLEIA GERAL ORDI- } \\
\text { NÁRIA }\end{array}$ & $14 / 08$ & Não \\
\hline & Ata & 52 & 3 & $\begin{array}{l}\text { ASSEMBLEIA GERAL EXTRA- } \\
\text { ORD. }\end{array}$ & $28 / 08$ & Não \\
\hline & Ata & 53 & 3 & $\begin{array}{l}\text { ASSEMBLEIA GERAL ORDI- } \\
\text { NÁRIA }\end{array}$ & $11 / 09$ & Não \\
\hline & Ata & 54 & 3 & $\begin{array}{l}\text { ASSEMBLEIA GERAL EXTRA- } \\
\text { ORD. }\end{array}$ & $25 / 09$ & Não \\
\hline & Ata & 55 & 3 & $\begin{array}{l}\text { ASSEMBLEIA GERAL ORDI- } \\
\text { NÁRIA }\end{array}$ & $09 / 10$ & Não \\
\hline & Ata & 56 & 3 & $\begin{array}{l}\text { ASSEMBLEIA GERAL EXTRA- } \\
\text { ORD. }\end{array}$ & $25 / 10$ & Não \\
\hline & Ata & 57 & 3 & $\begin{array}{l}\text { ASSEMBLEIA GERAL ORDI- } \\
\text { NÁRIA }\end{array}$ & $13 / 11$ & Não \\
\hline & Ata & 58 & 3 & $\begin{array}{l}\text { ASSEMBLEIA GERAL EXTRA- } \\
\text { ORD. }\end{array}$ & $20 / 11$ & Não \\
\hline & Ata & 59,60 & 3 & $\begin{array}{l}\text { ASSEMBLEIA GERAL ORDI- } \\
\text { NÁRIA }\end{array}$ & $27 / 11,11 / 12$ & Não \\
\hline & Ata & 61,62 & 3 & $\begin{array}{l}\text { ASSEMBLEIA GERAL EXTRA- } \\
\text { ORD. }\end{array}$ & $13 / 12,19 / 12$ & Não \\
\hline
\end{tabular}




\begin{tabular}{|c|c|c|c|c|c|c|}
\hline \multirow{15}{*}{2001} & Ata & 63 & 3 & $\begin{array}{l}\text { ASSEMBLEIA GERAL ORDI- } \\
\text { NÁRIA }\end{array}$ & 08/01 & Não \\
\hline & Ata & 64,65 & 3 & $\begin{array}{l}\text { ASSEMBLEIA GERAL EXTRA- } \\
\text { ORD. }\end{array}$ & $22 / 01,29 / 01$ & Não \\
\hline & Ata & 66 & 4 & $\begin{array}{l}\text { ASSEMBLEIA GERAL ORDI- } \\
\text { NÁRIA }\end{array}$ & $12 / 02$ & Não \\
\hline & Ata & 67 & 4 & $\begin{array}{l}\text { ASSEMBLEIA GERAL EXTRA- } \\
\text { ORD. }\end{array}$ & $22 / 02$ & Não \\
\hline & Ata & 68 & 4 & $\begin{array}{l}\text { ASSEMBLEIA GERAL ORDI- } \\
\text { NÁRIA }\end{array}$ & $12 / 03$ & Não \\
\hline & Ata & 69,70 & 4 & $\begin{array}{l}\text { ASSEMBLEIA GERAL EXTRA- } \\
\text { ORD. }\end{array}$ & $26 / 03,03 / 04$ & Não \\
\hline & Ata & 71,72 & 4 & $\begin{array}{l}\text { ASSEMBLEIA GERAL ORDI- } \\
\text { NÁRIA }\end{array}$ & 09/04, 23/04 & Não \\
\hline & Ata & 73 & 4 & $\begin{array}{l}\text { ASSEMBLEIA GERAL EXTRA- } \\
\text { ORD. }\end{array}$ & $25 / 04$ & Não \\
\hline & Ata & 74,75 & 4 & $\begin{array}{l}\text { ASSEMBLEIA GERAL ORDI- } \\
\text { NÁRIA }\end{array}$ & $14 / 05,28 / 05$ & Não \\
\hline & Ata & 76 & 4 & $\begin{array}{l}\text { ASSEMBLEIA GERAL EXTRA- } \\
\text { ORD. }\end{array}$ & $18 / 06$ & Não \\
\hline & Ata & 77 & 4 & $\begin{array}{l}\text { ASSEMBLEIA GERAL ORDI- } \\
\text { NÁRIA }\end{array}$ & $25 / 06$ & Não \\
\hline & Ata & 78 & 4 & $\begin{array}{l}\text { ASSEMBLEIA GERAL EXTRA- } \\
\text { ORD. }\end{array}$ & 04/07 & Não \\
\hline & Ata & 79,80 & 4 & $\begin{array}{l}\text { ASSEMBLEIA GERAL ORDI- } \\
\text { NÁRIA }\end{array}$ & $09 / 07,23 / 07$ & Não \\
\hline & Ata & 81 & 4 & $\begin{array}{l}\text { ASSEMBLEIA GERAL EXTRA- } \\
\text { ORD. }\end{array}$ & $06 / 08$ & Não \\
\hline & Ata & 82 a 91 & 4 & $\begin{array}{l}\text { ASSEMBLEIA GERAL ORDI- } \\
\text { NÁRIA }\end{array}$ & \begin{tabular}{|c|}
13 e $27 / 08,10$ e \\
$24 / 09,08$ e $22 / 10,12$ \\
e $26 / 11,10$ e $17 / 12$ \\
\end{tabular} & Não \\
\hline \multirow{3}{*}{2002} & Ata & 1 a 17 & 4 & $\begin{array}{l}\text { ASSEMBLEIA GERAL ORDI- } \\
\text { NÁRIA }\end{array}$ & $\begin{array}{l}14 \text { e } 28 / 01,18 / 02,11 \\
\text { e } 25 / 03,15 \text { e } 22 / 04, \\
13 \text { e } 27 / 05,10 \text { e } \\
24 / 06,11 \text { e } 22 / 07 \\
12 \text { e } 28 / 08,9 \text { e } 23 / 09\end{array}$ & Não \\
\hline & Ata & 18 & 4 & $\begin{array}{l}\text { ASSEMBLEIA GERAL EXTRA- } \\
\text { ORD. }\end{array}$ & $21 / 10$ & Não \\
\hline & Ata & 19 a 23 & 4 & $\begin{array}{l}\text { ASSEMBLEIA GERAL ORDI- } \\
\text { NÁRIA }\end{array}$ & $\begin{array}{l}\text { 28/10, } 11 \text { e } 25 / 11,9 \\
\text { e } 16 / 12\end{array}$ & Não \\
\hline
\end{tabular}




\begin{tabular}{|c|c|c|c|c|c|c|}
\hline \multirow{5}{*}{2003} & Ata & 1 a 6 & 4 & $\begin{array}{l}\text { ASSEMBLEIA GERAL ORDI- } \\
\text { NÁRIA }\end{array}$ & $\begin{array}{l}13 \text { e } 27 / 01,10 \text { e } \\
24 / 02,10 \text { e } 24 / 03\end{array}$ & Não \\
\hline & Ata & $07 /$ jan & 4 & $\begin{array}{l}\text { ASSEMBLEIA GERAL EXTRA- } \\
\text { ORD. }\end{array}$ & $31 / 03$ & Não \\
\hline & Ata & 8 a 10 & 4 & $\begin{array}{l}\text { ASSEMBLEIA GERAL ORDI- } \\
\text { NÁRIA }\end{array}$ & 14 e $28 / 04,12 / 05$ & Não \\
\hline & Ata & $11 /$ jan & 4 & $\begin{array}{l}\text { ASSEMBLEIA GERAL EXTRA- } \\
\text { ORD. }\end{array}$ & $19 / 05$ & Não \\
\hline & Ata & 12 a 25 & 4 & $\begin{array}{l}\text { ASSEMBLEIA GERAL ORDI- } \\
\text { NÁRIA }\end{array}$ & $\begin{array}{l}26 / 05,9 \text { e } 23 / 06,14 \\
\text { e } 28 / 07,11 \text { e } 25 / 08, \\
8 \text { e } 22 / 09,13 \text { e } 27 / \\
10,10 \text { e } 24 / 11,22 / 12\end{array}$ & Não \\
\hline \multirow{5}{*}{2004} & Ata & 1 a 7 & 4 & $\begin{array}{l}\text { ASSEMBLEIA GERAL ORDI- } \\
\text { NÁRIA }\end{array}$ & $\begin{array}{l}12 \text { e 26/01, 09/02, } 08 \\
\text { e 22/03, } 12 \text { e 26/04, }\end{array}$ & Não \\
\hline & Ata & 8 & 4 & $\begin{array}{l}\text { ASSEMBLEIA GERAL EXTRA- } \\
\text { ORD. }\end{array}$ & $03 / 05$ & Não \\
\hline & Ata & 9 a 20 & 4 & $\begin{array}{l}\text { ASSEMBLEIA GERAL ORDI- } \\
\text { NÁRIA }\end{array}$ & $\begin{array}{l}10 \text { e } 24 / 05,14 \text { e } \\
28 / 06,12 / 07,09 \text { e } \\
23 / 08,13 \text { e } 27 / 09, \\
25 / 10,08 \text { e } 22 / 11\end{array}$ & Não \\
\hline & Ata & $21 /$ jan & 4 & $\begin{array}{l}\text { ASSEMBLEIA GERAL EXTRA- } \\
\text { ORD. }\end{array}$ & $09 / 12$ & Não \\
\hline & Ata & 22,23 & 4 & $\begin{array}{l}\text { ASSEMBLEIA GERAL ORDI- } \\
\text { NÁRIA }\end{array}$ & 13 e $23 / 12$ & Não \\
\hline \multirow{8}{*}{2005} & Ata & 1 & 4 & $\begin{array}{l}\text { ASSEMBLEIA GERAL ORDI- } \\
\text { NÁRIA }\end{array}$ & $10 / 01$ & Não \\
\hline & Ata & 2 & 4 & $\begin{array}{l}\text { ASSEMBLEIA GERAL EXTRA- } \\
\text { ORD. }\end{array}$ & $17 / 01$ & Não \\
\hline & Ata & 3 a 8 & 4 & $\begin{array}{l}\text { ASSEMBLEIA GERAL ORDI- } \\
\text { NÁRIA }\end{array}$ & $\begin{array}{l}\text { 14/02, } 14 \text { e } 28 / 03,11 \\
\text { e } 25 / 04,09 / 05\end{array}$ & Não \\
\hline & Ata & 9 & 4 & $\begin{array}{l}\text { ASSEMBLEIA GERAL EXTRA- } \\
\text { ORD. }\end{array}$ & $16 / 05$ & Não \\
\hline & Ata & 10 a 15 & 4 & $\begin{array}{l}\text { ASSEMBLEIA GERAL ORDI- } \\
\text { NÁRIA }\end{array}$ & \begin{tabular}{|l}
$23 / 05,13$ e $27 / 06$ \\
$25 / 07,08$ e $22 / 08$ \\
\end{tabular} & Não \\
\hline & Ata & 16 & 4 & $\begin{array}{l}\text { ASSEMBLEIA GERAL EXTRA- } \\
\text { ORD. }\end{array}$ & $29 / 08$ & Não \\
\hline & Ata & 17 a 22 & 4 & $\begin{array}{l}\text { ASSEMBLEIA GERAL ORDI- } \\
\text { NÁRIA }\end{array}$ & $\begin{array}{l}\text { 26/09, } 10 \text { e } 24 / 10,14 \\
\text { e 28/11, } 12 / 12\end{array}$ & Não \\
\hline & Ata & 23 & 4 & $\begin{array}{l}\text { ASSEMBLEIA GERAL EXTRA- } \\
\text { ORD. }\end{array}$ & $21 / 12$ & Não \\
\hline
\end{tabular}




\begin{tabular}{|c|c|c|c|c|c|c|}
\hline \multirow{7}{*}{2006} & Ata & $1 \mathrm{e} 2$ & 4 & $\begin{array}{l}\text { ASSEMBLEIA GERAL ORDI- } \\
\text { NÁRIA }\end{array}$ & 09 e 23/01 & Não \\
\hline & Ata & 3 & 4 & $\begin{array}{l}\text { ASSEMBLEIA GERAL EXTRA- } \\
\text { ORD. }\end{array}$ & 08/02 & Não \\
\hline & Ata & 4 a 9 & 4 & $\begin{array}{l}\text { ASSEMBLEIA GERAL ORDI- } \\
\text { NÁRIA }\end{array}$ & $\begin{array}{l}13 \text { e } 27 / 03,10 \text { e } \\
24 / 04,08 / 05,12 / 06\end{array}$ & Não \\
\hline & Ata & 10 a 12 & 5 & REUNIÃO ORDINÁRIA & $10 / 07,14$ e $28 / 08$ & Não \\
\hline & Ata & 13 & 5 & $\begin{array}{l}\text { ASSEMBLEIA GERAL EXTRA- } \\
\text { ORD. }\end{array}$ & 04/09 & Não \\
\hline & Ata & 14 & 5 & $\begin{array}{l}\text { ASSEMBLEIA GERAL ORDI- } \\
\text { NÁRIA }\end{array}$ & $11 / 09$ & Não \\
\hline & Ata & 15 a 18 & 5 & REUNIÃO ORDINÁRIA & $\begin{array}{l}25 / 09,13 \text { e } 27 / 11, \\
11 / 12\end{array}$ & Não \\
\hline \multirow{3}{*}{2007} & Ata & 1 e 2 & 5 & REUNIÃO EXTRAORDINÁRIA & $15 / 01,12 / 02$ & Não \\
\hline & Ata & 3 a 16 & 5 & REUNIÃO ORDINÁRIA & $\begin{array}{l}12 \text { e } 26 / 03,23 / 04, \\
14 \text { e } 21 / 05,11 / 06, \\
09 \text { e } 23 / 07,27 / 08, \\
10 / 09,08 \text { e } 24 / 10, \\
26 / 11,10 / 12\end{array}$ & Não \\
\hline & Ata & 17 & 5 & $\begin{array}{l}\text { ASSEMBLEIA GERAL EXTRA- } \\
\text { ORD. }\end{array}$ & $17 / 12$ & Não \\
\hline 2008 & Ata & 1 a 16 & 5 & REUNIÃO ORDINÁRIA & $\begin{array}{l}25 / 02,10 / 03,14 / 04, \\
12 \text { e } 26 / 05,09 / 06,14 \\
\text { e 28/07, 25/08, } 08 \text { e } \\
22 / 09,13 / 10,10 \text { e } \\
24 / 11,15 \text { e } 22 / 12\end{array}$ & Não \\
\hline \multirow{9}{*}{2009} & Ata & 1 & 5 & $\begin{array}{l}\text { ASSEMBLEIA GERAL EXTRA- } \\
\text { ORD. }\end{array}$ & $0,3 / 02$ & Não \\
\hline & Ata & 2 e 3 & 5 & REUNIÃO ORDINÁRIA & $09 / 02,09 / 03$ & Não \\
\hline & Ata & 4 & 5 & $\begin{array}{l}\text { ASSEMBLEIA GERAL EXTRA- } \\
\text { ORD. }\end{array}$ & $19 / 03$ & Não \\
\hline & Ata & 5 & 5 & REUNIÃO ORDINÁRIA & $23 / 03$ & Não \\
\hline & Ata & 6 e 7 & 5 & REUNIÃO EXTRAORDINÁRIA & $30 / 03,27 / 04$ & Não \\
\hline & Ata & 8 e 9 & 5 & REUNIÃO ORDINÁRIA & $25 / 05,08 / 06$ & Não \\
\hline & Ata & 10 & 5 & REUNIÃO EXTRAORDINÁRIA & $18 / 06$ & Não \\
\hline & Ata & 11 a 20 & 5 & REUNIÃO ORDINÁRIA & $\begin{array}{l}13 \text { e } 27 / 07,10 \text { e } \\
24 / 08,14 \text { e } 28 / 09, \\
26 / 10,09 \text { e } 23 / 11, \\
14 / 12\end{array}$ & Não \\
\hline & Ata & 21 & 5 & REUNIÃO EXTRAORDINÁRIA & $21 / 12$ & Não \\
\hline
\end{tabular}




\begin{tabular}{|c|c|c|c|c|c|c|}
\hline \multirow{4}{*}{2010} & Ata & 1 a 8 & 5 & REUNIÃO ORDINÁRIA & $\begin{array}{l}11 / 01,22 / 02,08 \text { e } \\
22 / 03,12 \text { e } 26 / 04, \\
10 \text { e } 24 / 05\end{array}$ & Não \\
\hline & Ata & 9 e 10 & 5 & REUNIÃO EXTRAORDINÁRIA & 04 e $07 / 06$ & Não \\
\hline & Ata & 11 a 23 & 5 & REUNIÃO ORDINÁRIA & $\begin{array}{l}28 / 06 ; 12 \text { e } 26 / 07 ; 09 \\
\text { e } 23 / 08 ; 13 \text { e } 27 / 09 \text {, } \\
25 / 10 ; 8,10 \text { e } 22 / 11 ; \\
13 \text { e } 22 / 12\end{array}$ & Não \\
\hline & Ata & 24 & 5 & REUNIÃO EXTRAORDINÁRIA & $29 / 12$ & Não \\
\hline \multirow[b]{2}{*}{2011} & Ata & 1 & $\begin{array}{l}\text { Eletrô- } \\
\text { nica }\end{array}$ & REUNIÃO EXTRAORDINÁRIA & $18 / 01$ & Não \\
\hline & Ata & 2 a 20 & $\begin{array}{l}\text { Eletrô- } \\
\text { nica }\end{array}$ & REUNIÃO ORDINÁRIA & $\begin{array}{l}28 / 02,14 \text { e } 28 / 03, \\
11 / 04,09 \text { e } 23 / 05, \\
13 \text { e } 27 / 06,11 \text { e } \\
25 / 07,08 \text { e } 22 / 08 \\
12 \text { e } 26 / 09,10 / 10,14 \\
\text { e } 28 / 11,12 \text { e } 26 / 12\end{array}$ & \\
\hline \multirow{7}{*}{2012} & Ata & 1 & $\begin{array}{l}\text { Eletrô- } \\
\text { nica }\end{array}$ & REUNIÃO ORDINÁRIA & 09/01 & Não \\
\hline & Ata & 2 & $\begin{array}{l}\text { Eletrô- } \\
\text { nica }\end{array}$ & REUNIÃO EXTRAORDINÁRIA & $17 / 01$ & Não \\
\hline & Ata & 3 a 9 & $\begin{array}{l}\text { Eletrô- } \\
\text { nica }\end{array}$ & REUNIÃO ORDINÁRIA & $\begin{array}{l}13 / 02,12 \text { e } 26 / 03,09 \\
\text { e 23/04, } 14 \text { e } 28 / 05\end{array}$ & Não \\
\hline & Ata & 10 & $\begin{array}{l}\text { Eletrô- } \\
\text { nica }\end{array}$ & REUNIÃO EXTRAORDINÁRIA & $05 / 06$ & Não \\
\hline & Ata & 11 & $\begin{array}{l}\text { Eletrô- } \\
\text { nica }\end{array}$ & REUNIÃO ORDINÁRIA & $11 / 06$ & Não \\
\hline & Ata & 12 & $\begin{array}{l}\text { Eletrô- } \\
\text { nica }\end{array}$ & REUNIÃO EXTRAORDINÁRIA & $19 / 06$ & Não \\
\hline & Ata & 13 a 23 & $\begin{array}{l}\text { Eletrô- } \\
\text { nica }\end{array}$ & REUNIÃO ORDINÁRIA & $\begin{array}{l}25 / 06,09 / 07,13 \text { e } \\
27 / 08,10 \text { e } 24 / 09,08 \\
\text { e } 22 / 10,12 \text { e } 26 / 11, \\
10 / 12\end{array}$ & Não \\
\hline
\end{tabular}

Fonte: Cadastro de Conselhos de Saúde - 2007/2008

Disponível em: <http://formsus.datasus.gov.br/site/resultado.php?id_aplicacao=13\& filtro= $1 \&$ id_aplicacao_campo $=\&$ start_date $=\& e n d \_d a t e=\&$ campo $14973 \% 5 B \% 5 D=1643474>$. Ainda: <http://formsus.datasus.gov.br/site/resultado_detalhe.php?id_aplicacao=13\&id_aplicacao_ campo=389\&pagina $=4 \&$ num_por_pagina=100>. Acesso em,: 31 out. 2011. 
1 SARLET, Ingo Wolfgang; PETTERLE, Selma Rodrigues. Liberdade de pesquisa como direito humano e fundamental e seus limites: a pesquisa com seres humanos e os parâmetros protetivos estabelecidos pelo direito internacional e sua recepção no Brasil. Revista Espaço Jurídico, v. 15, 2014

2 LUNA, Florencia. Investigación. In: LUNA, Florencia; SALLES, Arleen L. F. (Orgs.). Bioética: nuevas reflexiones sobre debates clásicos. Buenos Aires: Fondo de Cultura Económica, 2008.

3 ROSENAU, Henning. Le conditions légales préalables requises pour les essais Clinique d'après la Declaration d'Helsinki révisée et la Convention Européenne sur les Droits de l'Homme et la Biomédecine. Journal International de Bioéthique. Nouvelles pratiques, nouvelles éthique de la recherche biomédical? 1.er partie. v. 15, n. 1, Mars. 2004.

4 PETTERLE, Selma Rodrigues. Liberdade de pesquisar, pesquisas clínicas e outras pesquisas científicas de risco envolvendo seres humanos: uma proposta de reformulação do atual sistema de controle implementado pelo Conselho Nacional de Saúde, à luz da Constituição Brasileira. 2012. 274 f. Tese (Doutorado em Direito) - Programa de Pós-Graduação em Direito, Pontifícia Universidade Católica do Rio Grande do Sul, Porto Alegre, 2012.

5 CIOMS. Diretrizes Éticas Internacionais para a Pesquisa Biomédica Envolvendo Humanos. Council for International Organizations of Medical Sciences Disponivel em: 〈http://www.cioms.ch/publications/ guidelines/guidelines nov 2002 blurb.htm>. Acesso em: 23 mai. 2011. RUIZ, Juana María Gil. Investigación médica en seres humanos. In: VALLEJO, Pilar Rivas, VALVERDE, María D. García (Org.). Derecho y Medicina. Cuestiones jurídicas para profesionales de la salud. Cizur Menor: Thomson Reuters: Aranzadi, 2009.

6 No original: "Sin embargo, estas organismos no gubernamentales tienen un papel de primer orden en el desarrollo de la ética médica y de la bioética, pues de su seno emanan normas internacionales, que ejercen una influencia innegable como principios inspiradores y orientadores de la actividad de los Comités Nacionales de Bioética, y en particular - a través de sus documentos de caráter deontológico y sus $\ll$ guías de bueno prática clínica〉 - en la actividad de los comités de ética hospitalarios y de ensayos clínicos". (FERNÁNDEZ, Juan Antonio Díez. Los comités nacionales de bioética: Legislación internacional y regulación en la nueva ley sobre investigación biomédica. Granada: Editorial Comares, 2007,p. 107).

7 Ibid., p. 107.

8 CHAVES, Antônio. Pesquisas em seres humanos. Revista de Informação Legislativa, Senado Federal, n. 108,1990

9 PETTERLE, 2013, op. cit.

10 SARLET, Ingo Wolfgang. A eficácia dos direitos fundamentais: uma teoria geral dos direitos fundamentais na perspectiva constitucional. 10. ed. rev. atual e ampl. Porto Alegre: Livraria do Advogado, 2009. BARROSO, Luís Roberto. Da Falta de Efetividade à Judicialização Excessiva: Direito à Saúde, Fornecimento Gratuito de Medicamentos e Parâmetros para a Atuação Judicial. In: SOUZA NETO, Cláudio Pereira de; SARMENTO, Daniel (Coords.). Direitos Sociais. Fundamentos, Judicialização e Direitos Sociais em Espécie. 2. tir. Rio de Janeiro: Editota Lúmen Júris, 2010.

11 FIGUEIREDO, op. cit. BARROSO, op. cit.

12 ESCOREL, Sarah; MOREIRA, Marcelo Rasga. Participação Social. In: GIOVANELLA, Lígia; ESCOREL, Sarah; LOBATO, Lenaura de Vaconcelos Costa et al (Org.). Política e Sistema de Saúde no Brasil. Rio de Janeiro: Editora FIOCRUZ, 2012. P. 853-883.

13 Ibid., p. 868.

14 CONFERÊNCIA NACIONAL DE SAÚDE, n. 8, 1986, Brasília, DF. Relatório Final. Brasília, 1986. Disponivel em: 〈http://conselho.saude.gov.br/biblioteca/relatorios/relatorio_8.pdf $\rangle$. Acesso em: 27 abr. 2015, p. 18

15 ESCOREL; MOREIRA, op. cit., p. 876.

16 Ibid., p. 875.

17 Ibid., p. 878.

18 GUIZARDI, Francini Lube et al. Participação da comunidade em espaços públicos de saúde: uma análise das conferências nacionais de saúde. Physis [online], 2004, v. 14, n. 1, pp. 15-39. Disponível em: < http:// www.scielo.br/pdf/physis/v14n1/v14n1a03.pdf>. Acesso em: 21 mai. 2015, p. 16.

19 CONFERÊNCIA MUNICIPAL DE SAÚDE. n. 12, 2003, Brasília, DF. Relatório Final. Brasília, 2004. Disponivel em: 〈http://conselho.saude.gov.br/biblioteca/Relatorios/relatorio_12.pdf〉. Acesso em: 21 mai. 2015.

20 CANOAS, Questionário pare a a 15 Conferencia [mensagem pessoal]. Mensagem recebida por: $<\mathrm{cms}$ canoas@gmail.com>em 14 abril 2015. 
21 CONFERÊNCIA NACIONAL DE SAÚDE, n. 12, 2003, Brasília, DF. Relatório Final. Brasília, 2004. Disponivel em: 〈http://conselho.saude.gov.br/biblioteca/Relatorios/relatorio_12.pdf〉. Acesso em: 21 mai. 2015, p. 148 .

22 Ibid., p. 179.

23 CONFERÊNCIA NACIONAL DE SAÚDE, 2004, op. cit., p. 136

24 Ibid., p. 137.

25 Ibid., p. 137.

26 Ibid., p. 142.

27 Ibid., p. 142.

28 Ibid., p. 142.

29 Ibid., p. 144.

30 CONFERÊNCIA NACIONAL DE SAÚDE, n. 13, 2007, Brasília, DF. Relatório Final. Brasília, 2008. Disponível em: 〈http://conselho.saude.gov.br/biblioteca/Relatorios/13cns_M.pdf>. Acesso em: 21 mai. 2015 , p. 35.

31 Ibid., p. 170.

32 CONFERENCIA NACIONAL DE SAÚDE, 2012, op. cit., p. 102.

33 Ibid., p. 109

34 Ibid., p. 114

35 ESCOREL; BLOCK [s.d] apud ESCOREL; MOREIRA, 2012, op. cit., p. 876.

36 DOMINGUEZ, op. cit., p.16

\section{RESEARCH INVOLVING HUMAN BEINGS AND THE SOCIAL CONTROL MECHANISMS}

\section{ABSTRACT}

The Brazilian Constitution of 1988 has protected a set of social rights, including the right to health. The brazilian health system is a single system that includes among its features the community participation, which occurs primarily through the health councils and conferences. In a national perspective, the National Health Council has been responsible for developing the guidelines that regulate researches involving human beings, most recently the Resolution 466/2012. Given these premises, this article aims to evaluate, by analyzing minutes of meetings and assemblies, whether or not the contents of this resolution have been discussed in the Municipality of Canoas/RS.

Keywords: Health. Social control. Research. Human beings.

Submetido: 19 out. 2015

Aprovado: 5 jan. 2016 